\title{
Erratum to: Investigating shrinkage and moisture diffusivity of melon seed in a microwave assisted thin layer fluidized bed dryer
}

\author{
Iman Golpour ${ }^{1}$ - Moein Zarrin Nejad ${ }^{2}$ - Reza Amiri Chayjan ${ }^{2}$. \\ Ali Mohammad Nikbakht ${ }^{3}$ Raquel P. F. Guiné R,5 $^{4}$ Majid Dowlati ${ }^{6}$
}

Published online: 20 January 2017

(C) Springer Science+Business Media New York 2017

\section{Erratum to: Food Measure}

\section{DOI 10.1007/s11694-016-9365-5}

The original version of this article unfortunately contained a mistake. The spelling of the corresponding author name Iman Golpour, was incorrectly published as Iman Goplour. The original article was corrected.

The online version of the original article can be found under doi:10.1007/s11694-016-9365-5.

Iman Golpour

Imangolpur@gmail.com

1 Young Researchers and Elite Club, Urmia Branch, Islamic Azad University, Urmia, Iran

2 Department of Biosystems Engineering, Faculty of Agriculture, Bu-Ali Sina University, Hamedan, Iran

3 Department of Mechanics of Biosystems, Faculty of Agriculture, Urmia University, Urmia, Iran

4 CI\&DETS, Polytechnic Institute of Viseu, Viseu, Portugal

5 CERNAS, Polytechnic Institute of Coimbra, Coimbra, Portugal

6 Department of Mechanical Engineering of Biosystems, Faculty of Agriculture, University of Jiroft, Jiroft, Iran 